\title{
Educação ambiental como fonte remediadora entre a interferência humana e a Flona de Nísia Floresta
}

\author{
Environmental education as a remedying source between human interference and the Nisia
}

\author{
Floresta Flona
}

La educación ambiental como fuente de remedio entre la interferencia humana y Nísia Floresta

Flona

Recebido: 24/06/2021 | Revisado: 06/07/2021 | Aceito: 09/07/2021 | Publicado: 21/07/2021

\author{
Isis Luana Torquato de Lima \\ ORCID: https://orcid.org/0000-0002-0218-067X \\ Universidade Federal do Rio Grande do Norte, Brasil \\ E-mail: Torquato.luana@gmail.com \\ Renata Cristina Medeiros Trajano de Araújo \\ ORCID: https://orcid.org/0000-0003-3943-8889 \\ Universidade Federal do Rio Grande do Norte, Brasil \\ E-mail: renatagro06@yahoo.com.br
}

\begin{abstract}
Resumo
A ocupação de áreas circunvizinhas a Unidades de Conservação não deve pôr em risco a prioridade dos objetivos da conservação. Para garantir essa prioridade, se faz necessário compatibilizar o uso dos recursos naturais e a conservação da área. Nesse contexto, ferramentas de Educação Ambiental podem auxiliar a manutenção do uso sustentável dessas áreas. Objetivou-se iniciar um trabalho de Educação Ambiental com os moradores circunvizinhos da Unidade de Conservação, revelando sua importância, como a sociedade pode interagir e promover caminhos para a conscientização ambiental local, respeitando-se as características coletivas e mostrando-se o quanto sua participação é essencial e efetiva para o sucesso, a longo prazo, na estratégia de conservação. Avaliou-se a percepção ambiental dos moradores da comunidade circunvizinha a Unidade, a qual situa-se na Área de Proteção Ambiental Bonfim/Guaraíra e realizou-se um levantamento de dados socioambiental através de questionários e visitas técnicas juntamente com a realização de uma ação de educação ambiental. Através da análise dos dados obtidos, contatou-se a falta de conhecimento dos moradores a respeito de conceitos básicos sobre o Meio Ambiente e que muitos ainda desconhecem a Unidade de Conservação Floresta Nacional de Nísia Floresta. Realizou-se atividades de cunho educacionais. Desta forma, compreendeu-se o quanto a percepção ambiental é um instrumento importante para interceptar a interação das comunidades que vivem no entorno das Unidades de Conservação e que a mesma deve ser amplamente utilizada como ferramenta de avaliação.
\end{abstract}

Palavras-chave: Unidades de conservação; Percepção ambiental; Conscientização.

\begin{abstract}
The occupation of areas surrounding Conservation Units should not jeopardize the priority of conservation objectives. To guarantee this priority, it is necessary to reconcile the use of natural resources and the conservation of the area. In this context, Environmental Education tools can help to maintain the sustainable use of these areas. The objective was to initiate an Environmental Education work with the surrounding residents of the Conservation Unit, revealing its importance and how society can interact and promote ways for local environmental awareness, respecting the collective characteristics and showing how much their participation is essential and effective for long-term success in the conservation. The environmental perception of the residents of the community surrounding the Unit was evaluated, which is located in the Bonfim / Guaraíra Environmental Protection Area and a survey of socioenvironmental data was carried out through questionnaires and technical visits together with the carrying out of an action of environmental education. Through the analysis of the obtained data, it was contacted the lack of knowledge of the residents about basic concepts about the Environment and that many are still unaware of the National Forest Conservation Unit of Nísia Floresta. Educational activities were carried out. In this way, it was understood how much the environmental perception is an important instrument to intercept the interaction of the communities that live around the Conservation Units and that it must be widely used as an assessment tool.
\end{abstract}

Keywords: Conservation units; Environmental perception; Awareness. 


\begin{abstract}
Resumen
La ocupación de áreas aledañas a las Unidades de Conservación no debe poner en peligro la prioridad de los objetivos de conservación. Para garantizar esta prioridad, es necesario conciliar el uso de los recursos naturales y la conservación del área. En este contexto, las herramientas de Educación Ambiental pueden ayudar a mantener el uso sostenible de estas áreas. El objetivo fue iniciar un trabajo de Educación Ambiental con los pobladores aledaños a la Unidad de Conservación, revelando su importancia y cómo la sociedad puede interactuar y promover formas de conciencia ambiental local, respetando las características colectivas y mostrando hasta qué punto su participación es esencial y efectiva por mucho tiempo. éxito a largo plazo en la estrategia de conservación basada en Unidades de Conservación. Avaliou-se a percepção ambiental dos moradores da comunidade circunvizinha a Unidade, a qual situase na Área de Proteção Ambiental Bonfim/Guaraíra e realizou-se um levantamento de dados socioambiental através de questionários e visitas técnicas juntamente com a realização de uma ação de educación ambiental. A través del análisis de los datos obtenidos, se contactó con el desconocimiento de los pobladores sobre conceptos básicos sobre Medio Ambiente y que muchos aún desconocen de la Unidad Nacional de Conservación Forestal de Nísia Floresta. Se llevaron a cabo actividades educativas. De esta manera, se entendió hasta qué punto la percepción ambiental es un instrumento importante para interceptar la interacción de las comunidades que viven alrededor de las Unidades de Conservación y que debe ser ampliamente utilizada como herramienta de evaluación.

Palabras clave: Unidades de conservación; Percepción ambiental; Conciencia.
\end{abstract}

\title{
1. Introdução
}

Nas últimas décadas, as questões ambientais ganharam maior força perante a sociedade, criando enorme relevância no sentido de conscientizar as pessoas e assegurá-las da importância da sustentabilidade do planeta para as gerações futuras através da preservação ambiental. Compatibilizar o uso de recursos naturais em diversas atividades antrópicas com a manutenção da qualidade ambiental é um dos grandes desafios da atualidade. Isso porque as atividades antrópicas são centradas na transformação energética e material e resultam irreversivelmente na geração de resíduos e de processos de degradação. A maneira mais comumente usada para controlar as ações antrópicas garantindo a qualidade ambiental é fiscalização e punição. Porém, em outro âmbito, nasce uma forma que vem promover a conscientização e o instinto protetor do meio ambiente através da educação, denominada Educação Ambiental (Cunha, 2008).

A educação ambiental teve seus primeiros passos no início da década de 70, com a existência de movimentos conservacionistas. Mais precisamente em 1973, houve o processo de institucionalização da Educação Ambiental no Governo Federal brasileiro, com a criação da Secretaria Especial do Meio Ambiente, vinculada à Presidência da República (Henriques, et.al., 2007). Em 27 de Abril de 1999, foi instituída a Lei 9.795 que cria a Política Nacional de Educação Ambiental (PNEA) e enfatiza em seu art. $2^{\circ}$ que a "Educação Ambiental é um componente essencial e permanente da educação nacional, devendo estar presente, de forma articulada, em todos os níveis e modalidades do processo educativo, em caráter formal e não-formal" (Brasil, 1999).

Uma das formas de promover a Educação Ambiental (EA) é através do uso dos espaços territoriais especialmente protegidos. Com o objetivo de também promover a EA foi criado as Unidades de Conservação através da Lei ${ }^{\circ} 9.985$ de 18 de Julho de 2000, que instituiu o Sistema Nacional de Unidades de Conservação da Natureza (SNUC) e conceituou Unidade de Conservação (UC) como "espaço territorial e seus recursos ambientais, incluindo as águas jurisdicionais, com características naturais relevantes, legalmente instituído pelo Poder Público, com objetivos de conservação e limites definidos, sob regime especial de administração, ao qual se aplicam garantias adequadas de proteção" (Brasil, 2000). Cada Unidade de Conservação possui sua importância ambiental para sua respectiva região.

No entanto, a criação das UCs não foi suficiente como medida de conservação ambiental e em 2007 foi criada por meio da Lei 11.516 de 28 de agosto de 2007 o Instituto Chico Mendes de Conservação da Biodiversidade- ICMBio, com o objetivo de dar foco a gestão de Unidades de Conservação Federais e à conservação da biodiversidade existente nesses territórios protegidos por lei (Brasil, 2007). 
As Unidades de Conservação são alvos de vários tipos de pressão por parte de comunidades em seu entorno, constituído por ações invasivas, extração de produtos naturais, desmatamentos, caças predatórias, entre outros, comprometendo assim os recursos naturais e conservacionistas das UCs (Milano, 2000).

Diante desse cenário é válido procurar artifícios para colaborar com a conservação dessas áreas. Partindo da concepção de que a Floresta Nacional (Flona) de Nísia Floresta é um importantíssimo espaço multiplicador de conhecimento, promovendo-se reflexões sobre o meio ambiente, objetivando-se direcionar a população para a conscientização ambientalmente correta e sobre a necessidade de conservá-la.

A importância da inserção da conscientização ambiental como forma de promover mudanças e hábitos nas comunidades próximas a Unidades de Conservação foram constatadas e expressadas por Torres \& Oliveira (2008). O interesse por envolver as comunidades locais em esforços conservacionistas não é novidade e vem sendo debatido há algum tempo (Dalle \& Potvin, 2004). Estudos relatam a necessidade e urgência de práticas de Educação Ambiental nessas comunidades, pois somente a partir da inserção da EA é que ocorrerá a transformação e a concretização da conscientização ambiental. (Marques \& Coutinho, 2008).

As ações com as comunidades possibilitam compreender melhor o ambiente em que se está inserida e propor soluções para a conservação da biodiversidade local. De fato, sensibilizar e despertar a consciência crítica de grupos sociais no entorno das Unidades de Conservação e estimular a participação dos mesmos na proteção dos recursos naturais, têm sido consideradas as ações mais pertinentes para a efetiva proteção dessas áreas (Maroti, 2002; Tabanez, et al.,1997).

A concepção, critérios e normas que instituem as Unidades de Conservação negam que haja interação entre grupos próximos a esses espaços protegidos, por isso que comunidades no entorno das UCs se sentem restritas ao seu uso, causando nelas uma impressão negativa sobre as UCs, desfazendo assim qualquer empenho relacionado a uma boa vizinhança em busca do uso sustentável e principalmente de preservação (Loureiro, 2008).

Fortalecer a Educação Ambiental através de práticas educativas e fundamentar a importância para o sucesso da preservação da UC é de grande valia para a interação e participação ativa da comunidade juntamente com a Unidade, proporcionando resoluções coletivas para possíveis problemas adquiridos com o passar do tempo, e sempre com o intuito de reduzir a degradação ambiental na região de influência da UC advindos do mal-uso da Flona.

O presente trabalho trouxe uma nova concepção para a comunidade próxima a Flona, através de práticas de educação ambiental enfatizando a gestão ambiental, refletindo sobre o comportamento ético que a sociedade espera, considerando o contexto social, econômico e cultural através da valorização a inter-relação sadia entre Sociedade-Ambiente-CiênciaTecnologia (Carvalho, 2006).

Objetivou-se realizar um trabalho enfático de Educação Ambiental com os moradores circunvizinhos da Unidade de Conservação, revelando-se a importância das UCs e de como a sociedade pode interagir e promover caminhos para a conscientização ambiental local, de modo que seja mantida suas características coletivas e demonstrar o quanto sua participação é essencial e efetiva para o sucesso, a longo prazo, da estratégia de conservação baseada nas premissas das Unidades de Conservação.

\section{Metodologia}

\section{1 Área de estudo}

A área de estudo abrange a Unidade de Conservação Floresta Nacional (Flona) de Nísia Floresta, criada a partir do Decreto de 27 de setembro de 2001 (Brasil, 2001). É uma Unidade de Conservação do tipo Uso sustentável, pois permitem atividades que envolvam coleta e uso dos recursos naturais, mas desde que praticadas de forma que a perenidade dos recursos ambientais renováveis esteja assegurada (MMA, 2017). 
A Flona de Nísia Floresta tem o objetivo de "promover o manejo adequado dos recursos naturais, garantir a proteção dos recursos hídricos e belezas cênicas e fomentar o desenvolvimento da pesquisa científica, com ênfase à sua exploração sustentável" (Brasil, 2001).

Está inserida na Área de Proteção Ambiental (APA) Bonfim/Guaraíra, criada pelo Decreto Estadual n ${ }^{\circ}$ 14.369/99 (Brasil, 2012), localizada em Nísia Floresta/RN, distanciando-se $3 \mathrm{~km}$ da sede do município e $38 \mathrm{~km}$ da capital do estado do RN, Natal. O clima da região da Flona é do tipo tropical com estação seca de inverno (Aw), com variação de temperatura de 20 a $27^{\circ} \mathrm{C}$ (Alvares, 2014). Quanto à geomorfologia e geologia, o município está inserido na área de abrangência do Grupo Barreiras, com idade do Terciário Superior, onde predominam argilas, arenitos, arenitos conglomeráticos, siltitos, arenitos caulínicos inconsolidados e mal selecionados (Brasil, 2012). A área é caracterizada por Neossolo Quartzarênico, que é um solo bastante arenoso com fertilidade natural muito baixa, pobre em macro e micronutrientes (Embrapa, 1971).

Com 174,95 hectares, a Floresta possui importância em seu contexto regional, por ser um dos poucos fragmentos de Mata Atlântica existente, além disso, são significativos os desafios de sua gestão e manejo como entidade fomentadora do desenvolvimento sustentável na região (Brasil, 2012). O bioma Mata Atlântica é um dos mais ameaçados no Brasil e no mundo.

Há aproximadamente 50 metros desta Unidade (Figura 1) foi instalado um loteamento denominado "Conjunto Alto do Coqueiral" com a construção de 200 moradias do programa Minha casa Minha vida que é uma iniciativa do Governo Federal através do Decreto $N^{\circ} 7499$, de 16 de junho de 2011 e tem por finalidade criar mecanismos de incentivo à produção e à aquisição de novas unidades habitacionais, à requalificação de imóveis urbanos, para famílias com renda mensal de até $\mathrm{R} \$$ 5.000,00 (cinco mil reais) (Brasil, 2011).

O loteamento vem acarretando problemas para a continuidade da Unidade, causando um aumento na pressão antrópica com risco de isolamento e comprometimento da integridade da mesma a curto e médio prazo, de acordo com o plano de manejo da Flona. 
Figura 1 - Mapa de Localização da Unidade de Conservação Floresta Nacional de Nísia Floresta e do Conjunto alto do coqueiral no município de Nísia Floresta/RN.

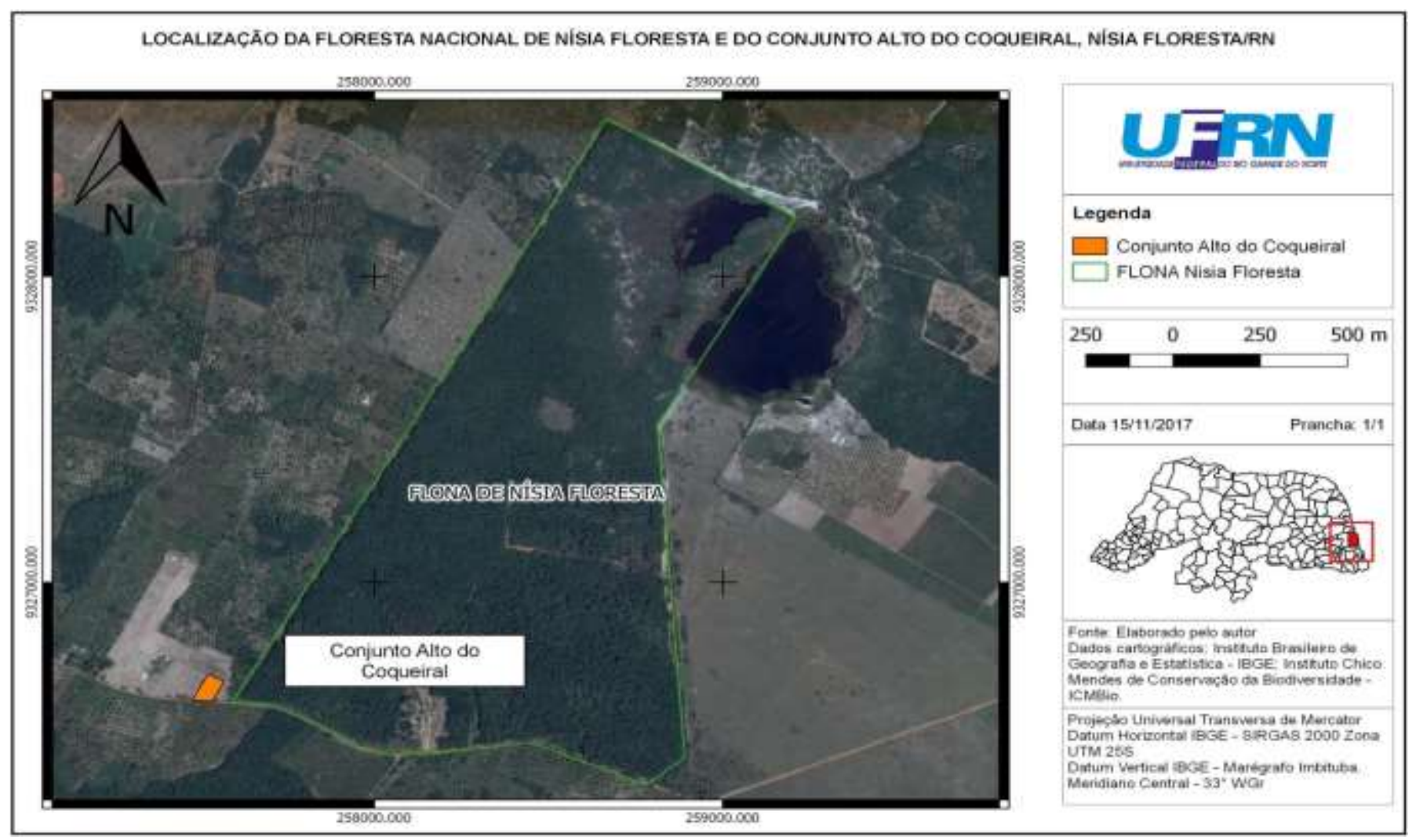

\subsection{Levantamento de dados}

O levantamento de dados da pesquisa dividiu-se em 3 (três) etapas que envolveram 4 (quatro) encontros com a comunidade, conforme descrição a seguir:

\subsubsection{Reconhecimento da área}

Iniciou-se o primeiro momento de encontro com a comunidade e coleta de dados realizando-se informalmente o reconhecimento da área como descrito e adaptado por Jesus e Bedritrichuk (2018). Logo após, foram realizadas apresentações e conversas informais com moradores locais, objetivando conhecer mais profundo a cultura e dinâmica que envolve o loteamento, assim como suas perspectivas referente a unidade em questão. Realizou-se uma pesquisa formal de carácter qualitativa, como descrita por Richardson (2014) levando em consideração a percepção ambiental, sobre as motivações da comunidade, em compreender e interpretar determinados comportamentos, a opinião e as expectativas dos indivíduos da população. De acordo com Minayo e Costa (2018) essa é uma filosofia estruturante, pois constitui uma perspectiva circular que possibilita aprofundar o conhecimento da realidade e a recria teoricamente.

\subsubsection{Aplicação de questionários participativos}

Em um segundo momento, priorizou-se apontar numericamente a frequência e a intensidade dos comportamentos dos indivíduos da comunidade local (Minayo, 2008) para compreender-se qualitativamente e quantitativamente a comunidade foram feitas entrevistas (Almeida, et al., 2017) que de acordo com Minayo (2015) é uma "conversa com finalidade". Dessa forma, a coleta de dados foi iniciada através da técnica de aplicação de questionários participativos, além da observação e do registro fotográfico. A aplicação do questionário foi realizada em cada unidade familiar, com a participação de um 
representante do desta unidade, maior que 18 anos. A população amostral foi composta de 115 entrevistados ou unidade familiar.

Os questionários foram compostos por perguntas de respostas abertas e também com múltiplas escolhas (Tabela 1). As perguntas abertas foram utilizadas para o levantamento de dados sociais e as de múltiplas escolhas foram utilizadas para o levantamento de dados ambientais. As alternativas de múltipla escolha foram apresentadas várias alternativas e o entrevistado poderia escolher uma resposta simples (apenas uma alternativa), em algumas outras questões, respostas múltiplas (mais de uma alternativa), desta maneira e dadas a diversidade de respostas, possibilitou-se entender o pensamento sobre percepção ambiental da comunidade envolvida, proporcionando a busca por alternativas que contribuam com a transformação da realidade local, associada a uma experiência educativa concreta que tenha a mudança como seu eixo central (Vasco \& Zakrzevski, 2010).

Tabela 1 - Levantamento socioambiental do loteamento Alto do Coqueiral - Comunidade do entorno da Floresta Nacional de Nísia Floresta.

\begin{tabular}{|c|c|}
\hline $\begin{array}{l}\text { QUESTÕES - DADOS E PERCEPÇÃO AMBIENTAL DO } \\
\text { ENTREVISTADO }\end{array}$ & RESPOSTAS \\
\hline 1. Gênero & Feminino, masculino \\
\hline 2. Idade & $\begin{array}{l}\text { Até } 18 \text { anos, 18-25 anos, 26-30 anos, 31-35 anos, 36-40 anos, } \\
41+\text { anos }\end{array}$ \\
\hline 3. Trabalha? Em caso positivo, qual sua ocupação? & Sim, não -------------------- \\
\hline 4. Mais alguém na família trabalha? Em caso positivo, qual a ocupação? & Sim, não ------------------- \\
\hline 5. Qual seu horário de trabalho? & Resposta aberta \\
\hline 6. Quantas pessoas moram na residência? & Resposta aberta \\
\hline 7. Quantas são crianças (até 12 anos)? & Resposta aberta \\
\hline 8. Qual seu interesse em assuntos relacionados ao Meio Ambiente? & $\begin{array}{l}\text { Muito interessado, razoavelmente interessado, pouco interessado, } \\
\text { nenhum interesse, não sei }\end{array}$ \\
\hline 9. Você sabe o que é Educação Ambiental? & Sim, não \\
\hline 10. Você sabe o que é Unidade de Conservação? & Sim, não \\
\hline $\begin{array}{l}\text { 11. Você já ouviu falar no Instituto Chico Mendes de Conservação da } \\
\text { Biodiversidade - ICMBio? }\end{array}$ & Sim, não \\
\hline $\begin{array}{l}\text { 12. Você conhece a Floresta Nacional (Flona) de Nísia Floresta? Em } \\
\text { caso negativo, tem vontade de conhecer? }\end{array}$ & Sim, não; Sim, não \\
\hline $\begin{array}{l}\text { 13. Qual sua opinião sobre a Flona de Nísia Floresta (admitem-se } \\
\text { múltiplas respostas) }\end{array}$ & $\begin{array}{l}\text { É importante para proteger a natureza (animais e plantas), é uma } \\
\text { área sem importância, é uma área onde são feitas pesquisas } \\
\text { científicas, é uma área que tem fiscalização }\end{array}$ \\
\hline $\begin{array}{l}\text { 14. Você gostaria de participar de uma ação de Educação Ambiental? Se } \\
\text { sim, prefere na Unidade de Conservação ou na comunidade? }\end{array}$ & Sim, não; Resposta aberta \\
\hline 15. Existe serviço de coleta de resíduos sólidos (lixo) na comunidade? & Sim, não, não soube avaliar, não respondeu \\
\hline 16. Qual a frequência da coleta domiciliar de lixo: & $\begin{array}{l}\text { Diariamente, uma vez por semana, duas vezes por semana, três } \\
\text { vezes por semana, não há coleta de lixo, não soube avaliar }\end{array}$ \\
\hline 17. Existe a coleta seletiva de resíduos? & Sim, não, não soube avaliar, não respondeu \\
\hline 18. Tipo de coleta seletiva de resíduos (admitem-se múltiplas respostas) & Metal, papel/papelão, plástico, vidro, outra, não soube avaliar \\
\hline 19. Possui animal doméstico? Em caso positivo, qual? & Sim, não ------------- \\
\hline 20. Você sabe o que é crime ambiental? & Sim, não \\
\hline
\end{tabular}




\subsubsection{Ações de Educação Ambiental}

Após o levantamento de dados foram propostas ações de Educação Ambiental que contribuiriam com o direcionamento da construção de uma conscientização ambiental, realizou-se estratégias de exposições explanativas e oficinas voltadas para a difusão de conhecimento e direcionamento de conscientização de proteção ambiental, comungando com o que Rodrigues (2019), revelou em sua pesquisa.

As oficinas realizadas foram trabalhadas seguindo os princípios da PNEA e como práticas de educação ambiental voltadas para o público infanto-juvenil, às quais de acordo com Rodrigues (2019) são multiplicadoras de informações e consequentemente tornam-se adultos mais comprometidos com o meio em que vivem. Desta forma, esse público absorve e incentiva as práticas de conscientização ambiental e produz a formação natural de agentes multiplicadores das experiências vividas nos eventos (Ambiental, 2011), como também para o público adulto.

\section{Resultados e Discussão}

O perfil socioambiental dos moradores da comunidade no entorno da Flona, mostra que a comunidade estudada é composta principalmente por adultos, na faixa entre 26 e 30 anos de idade. A porcentagem dividiu-se em até 18 anos foram $13 \%$, de 18 a 25 foram $20 \%$, entre 26 a 30 anos foi 32\%, de 31 a 35 foram 17\%, de 36 a 40 anos foi de 5\% e acima de 41 anos foram $13 \%$, totalizando $100 \%$ dos entrevistados. A maioria dos entrevistados demostraram interesses relacionados ao meio ambiente (Figura 2) indicando suas receptividades as ações voltadas para a sustentabilidade ambiental de Unidades de Conservação. 
Figura 2 - Interesse dos moradores da comunidade Alto do Coqueiral, localizada na circunvizinhança da Unidade de Conservação Floresta Nacional de Nísia Floresta, no município de Nísia Floresta/RN, em assuntos relacionados ao Meio Ambiente.

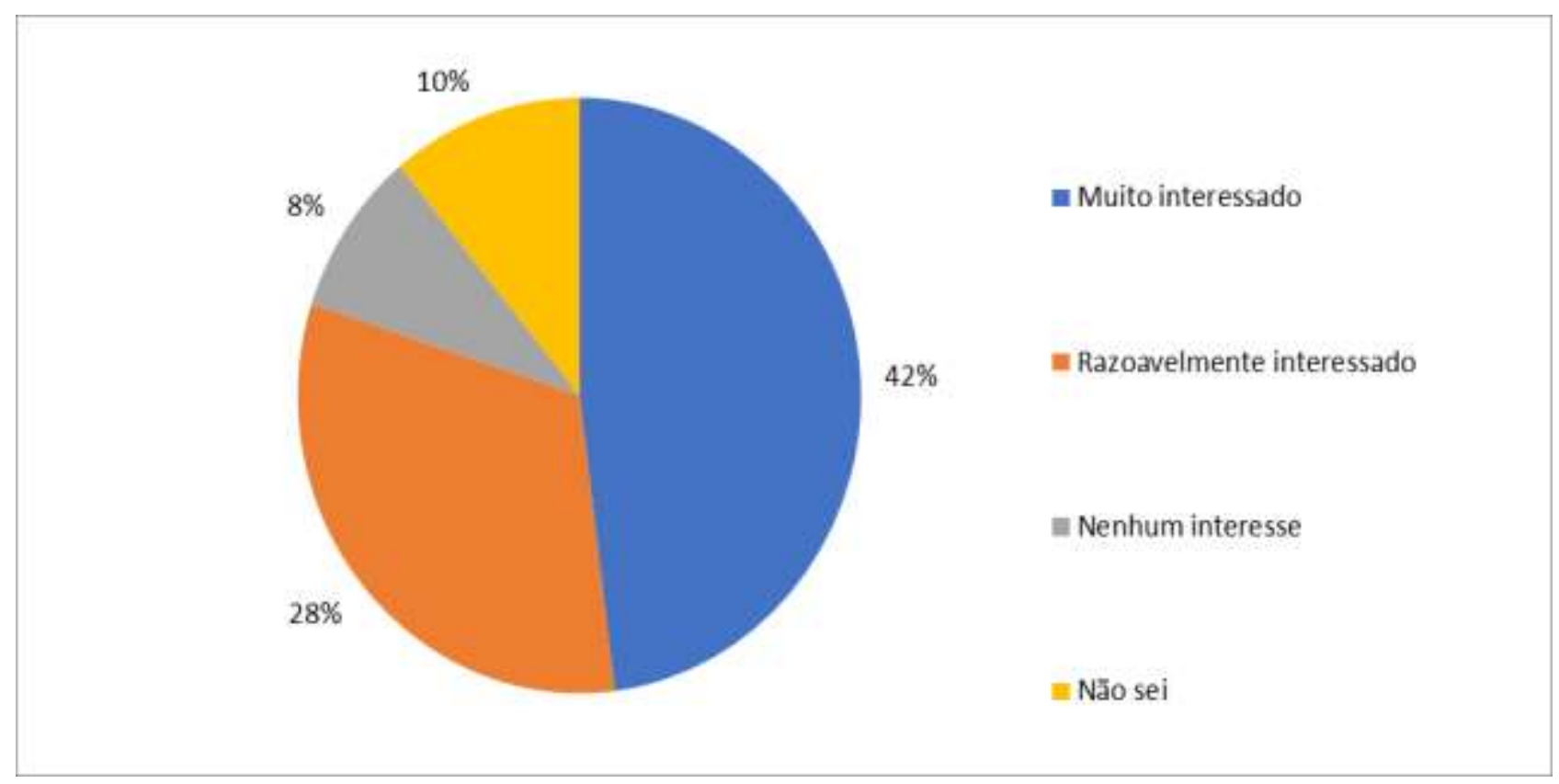

Fonte: Autores.

Embora demonstrem interesse em temas voltados ao meio ambiente, 67\% dos entrevistados afirmaram não saber o que é Educação Ambiental e $72 \%$ alegaram não saber sobre a Unidade de Conservação. Este resultado revela que o acesso dessa comunidade a debates relacionados ao tema é limitado o que pressupõem um desafio para aproximarmos a comunidade e trazer a educação ambiental como fonte remediadora entre a interferência humana e a Unidade de Conservação. Após iniciado o diálogo com comunidades locais em Unidades de Conservação é possível identificar avanços no que diz respeito à apropriação de conhecimentos pela comunidade e, consequentemente, ao uso sustentável dos recursos naturais no entorno dessas unidades (Carregosa, et al., 2015).

Grande parte dos entrevistados disseram que nunca tinham ouvido falar no Instituto Chico Mendes de Conservação da Biodiversidade- ICMBio e relacionavam a Unidade de Conservação apenas ao Instituto Brasileiro do Meio Ambiente e dos Recursos Naturais Renováveis- IBAMA (Antigo Órgão responsável pela Unidade de Conservação), evidenciando que apesar da convivência e ocupação tão próxima a unidade não havia informações e reconhecimento adequados a respeito da importância da área (Souza, et al., 2015).

Neste tocante, dos 115 entrevistados, 67 (sessenta e sete) afirmaram não conhecer a Flona de Nísia Floresta, mas $82 \%$ dos questionados revelaram grande interesse em conhecê-la. Evidenciando-se que o planejamento e a realização das ações de educação encontrariam a facilidade de contar com o apoio da comunidade. Vale ressaltar que a participação dessas comunidades na gestão dessas áreas tem sido considerada premissa fundamental para o sucesso dessa estratégia em longo prazo (Carregosa, et al., 2015).

Porém, historicamente os conflitos e a falta de diálogo entre esses meios, em áreas protegidas, geram um afastamento entre estes, o que dificulta a resolução dos problemas (MMA, 2004). Trabalhos como este facilitam a resolução desses problemas, o envolvimento da comunidade e o reconhecimento da importância da conservação desses espaços.

Apesar de a maioria relatar desconhecimento da Unidade, não deixaram de admitir a importância da Flona para a comunidade e para o Meio Ambiente e explanaram opiniões afirmando que a Flona era importante para proteger a natureza, 
que era uma área onde eram feitas pesquisas científicas e uma área que tem fiscalização (Figura 3). Sobre a limpeza e destinação dos resíduos sólidos, todos os entrevistados afirmaram ter serviço de coleta dos resíduos na comunidade e que os recolhimentos são realizados duas vezes por semana. A maior parte de resíduos produzidos pelo loteamento são papel/papelão e plásticos, mas apesar da grande quantidade de materiais passíveis de reciclagem, 100\% dos entrevistados afirmaram não haver a coleta seletiva dos resíduos nas unidades familiares.

A geração de resíduos é influenciada pelo número de habitantes, condições climáticas, hábitos e costumes da população (Lima, 1995). Mas por outro lado, a coleta seletiva juntamente com a reciclagem está cada vez mais sendo praticada e difundida em todo o mundo e aos poucos as pessoas estão descobrindo que muito do que descartamos não é lixo (Hirama \& Silva, 2009). A educação ambiental tem mostrado também resultados positivos nessa temática, uma vez que possibilitou a conscientização da importância do meio ambiente a fim de transmitir conceitos e valores sobre o tema determinado, além de transmitir o fato de que a educação ambiental é o instrumento necessário e eficaz para promover a mudança de paradigma da sociedade e consequentemente o alcance para o desenvolvimento sustentável (Pinto, et al., 2015). A comunidade além de preservar o meio ambiente ainda pode gerar renda extra e oportunidade de emprego, através da reciclagem desses materiais.

Figura 3 - Opinião dos moradores da comunidade Alto do Coqueiral, localizada na circunvizinhança da Unidade de Conservação Floresta Nacional de Nísia Floresta, no município de Nísia Floresta/RN, sobre a Flona de Nísia Floresta.

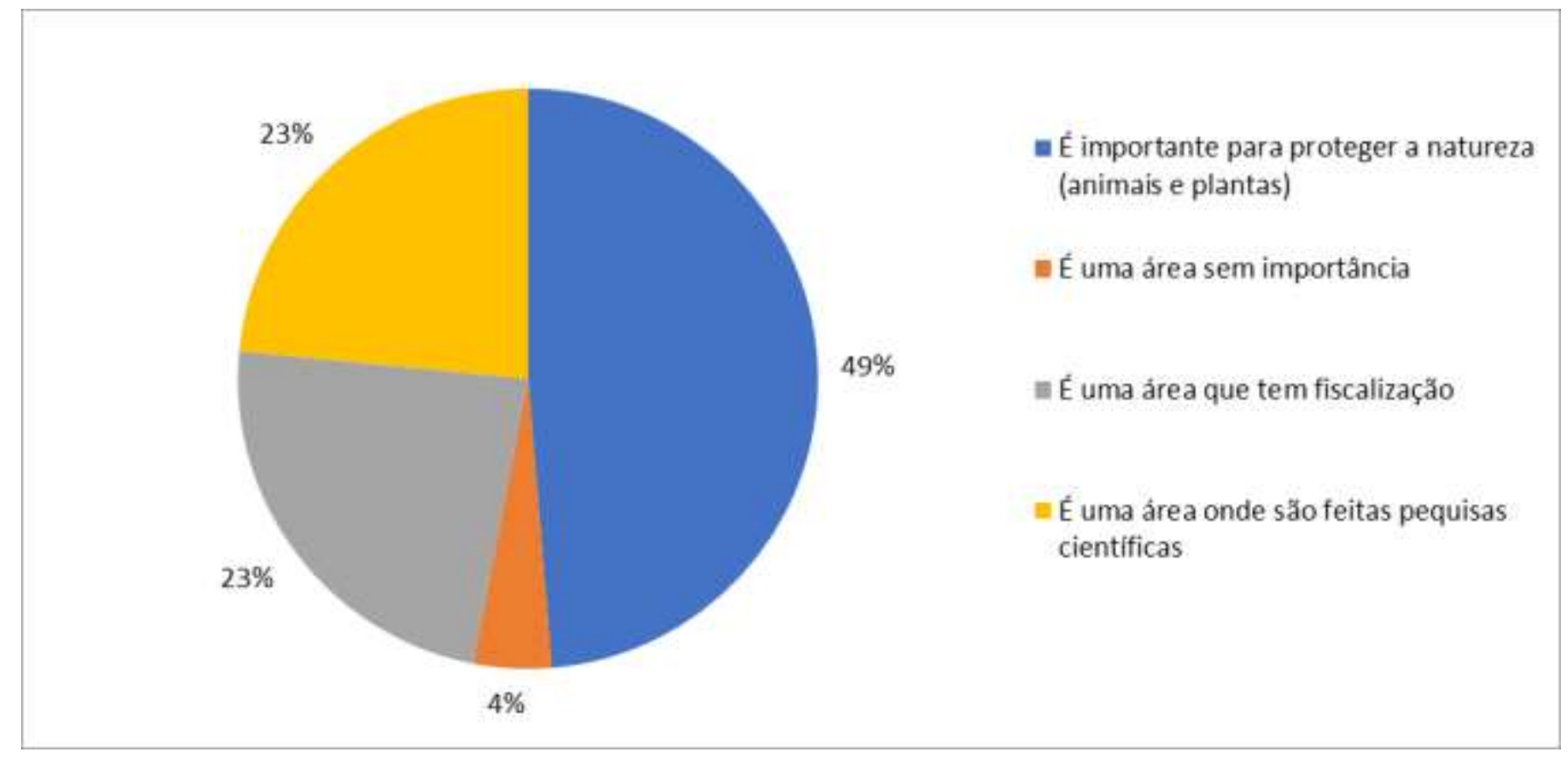

Fonte: Autores.

Se tratando da biodiversidade, ficou claro que os moradores têm uma cultura de criação de animais domésticos, como gatos e cachorros e até mesmo a criação de animais silvestres de forma clandestina, que de acordo com o artigo 29 da Lei $\mathrm{N}^{\circ}$ 9.605 de 12 de fevereiro de 1998 constitui-se como crime ambiental (Brasil, 1998). Desta forma, a coleta de dados mostrou que 55\% dos moradores possuem estes animais, mesmo sabendo que existe proibição e que a caça é considerada crime ambiental. No tocante ao crime ambiental, 59\% dos entrevistados alegaram saber o que são crimes ambientais, mas quando questionados mais a finco, estes não souberam descrever de forma concisa. 
A falta de conhecimento das pessoas sobre simples questões cotidianas torna o acolhimento das fiscalizações difíceis de serem aceitas pela comunidade, como é o caso de crimes ambientais, mais por outro lado essa falta de acolhimento pode trazer ações de autuação, dando início a um processo que podem lhe causar grandes transtornos (Cunha, 2008).

Por fim, foi questionado se o entrevistado gostaria de participar de uma ação de Educação Ambiental e 83\% dos entrevistados mostraram interesse em participar.

Ao serem questionados a respeito de em que local gostaria de participar da ação, 35\% afirmaram que gostariam de participar da ação na UC e $46 \%$ optaram por ser realizada na comunidade, por motivos de facilidade e comodidade de acesso a todos os participantes.

A partir do resultado dos questionários pôde-se ter uma noção do perfil socioambiental da comunidade, revelando que muitos ainda desconhecem os conceitos de conservação e preservação do meio ambiente tanto quanto a importância da Unidade de Conservação para com a comunidade e através desses resultados foi pensada como seria proposta a ação de educação ambiental.

No encontro seguinte (terceiro encontro) foi feita uma mobilização social para poder despertar o interesse e a curiosidade da comunidade perante o trabalho de ação de educação ambiental que seria realizado posteriormente. Foi realizado um trabalho de educação informal, a campanha foi realizada através de um veículo de comunicação, distribuição de folders nas unidades familiares e chamadas na rádio local para complementar a propaganda.

Após o resultado destes questionários e a receptividade do terceiro encontro, articulou-se junto a direção da Unidade de Conservação uma proposta pedagógica, baseado no eixo situacional, onde foi realizado o diagnóstico da região do entorno através do questionário antes comentado; no que se refere o eixo conceitual, utilizou-se de referências e diretrizes utilizadas pela a coordenação de Educação Ambiental da FLONA e pelo PNEA, que serviram para estruturar a estratégia operacional. A operação foi realizada em parceria com a UC de Nísia Floresta e a Universidade Federal do Rio Grande do Norte.

No quarto e último encontro, realizou-se a ação operacional de Educação Ambiental como fonte remediadora. Ocorreram oficinas englobando vários aspectos ambientais, com o intuito de buscar a sensibilização e conscientização da comunidade diante do meio ambiente e da UC envolvida. Foram realizadas exposições de répteis e anfíbios que estão presentes na fauna local e regional, exposição de banners do Instituto Chico Mendes de Conservação da Biodiversidade- ICMBio para esclarecer a comunidade a importância da UC e despontar sobre o Bioma Mata Atlântica e o importante papel do ICMBio para o meio ambiente. Todas as oficinas realizadas foram pensadas e organizadas de acordo com o resultado dos questionários, tentando englobar, ao máximo, todos os problemas vistos na comunidade, como forma de propor alternativas que venham minimizar possíveis impactos ambientais.

Dentro das oficinas realizadas, ressalta-se três oficinas e uma exposição de répteis e anfíbios. A primeira oficina é a de produção de Puffs de garrafas pets: Com o intuito de diminuir os resíduos sólidos gerados pela comunidade, foi pensada em uma atividade que pudesse trazer benefícios para o meio ambiente. A oficina enfatizou-se os 3Rs (reduzir, reutilizar e reciclar) através da reciclagem, que de acordo com Araújo (2017) é uma metodologia que se torna cada vez mais eficiente e imprescindível para um modo de vida mais responsável. A reciclagem além de preservar os recursos naturais é uma alternativa para gerar renda para a população. O objetivo da oficina foi trazer para o cotidiano dos moradores da comunidade, maneiras de como reduzir o lixo produzido em suas residências e como reutilizar as garrafas pets ao invés de as descartarem, assim reduzindo a quantidade de resíduos sólidos produzidos.

Outra oficina em destaque foi a produção de mudas, que foi dividida em dois momentos: inicialmente houve uma conversa para esclarecimento de informações sobre plantas exóticas e a importância da produção de mudas nativas, assim como a produção de mudas como atividade econômica, logo após, utilizando-se da estratégia descrita por Novaes (2019), foi realizada a produção de mudas e cada morador envolvido pôde produzir sua muda como forma de aproximação e 
conscientização da importância das mesmas na natureza. O objetivo dessa oficina foi capacitar a comunidade do entorno da Flona sobre as variadas técnicas de formas de produção de mudas, esclarecer aos participantes acerca das questões ambientais e da importância da preservação ambiental e do cultivo de plantas, produzir mudas com fins paisagísticos e alimentícios (frutíferas) e estimular os moradores a manter, preservar e disseminar o conhecimento adquirido durante as atividades.

A oficina de Produção de hortas orgânicas foi bastante apreciada, pois como forma de atingir todo público alvo da comunidade, foi pensada no plantio de hortas em pequenos espaços, que segundo Clemente \& Haber (2012) é uma alternativa para as pessoas que não possuem em suas casas espaço suficientes para uma horta em canteiros, que é o método tradicional. Primeiramente houve uma explicação de fatores que afetam as plantas através de linguagem simples e prática para facilitar o entendimento dos participantes. Foi abordado também sobre a conexão entre o reaproveitamento dos resíduos e compostagem, uma vez que a produção da horta foi feita em garrafas pets. O objetivo da oficina foi proporcionar a comunidade o conhecimento sobre a produção de hortas orgânicas com a intenção de estabelecer um maior contato com a natureza e o incentivo ao consumo de alimentos saudáveis, enxergar uma possibilidade para produção e manutenção de hortas gerando renda para as famílias e conscientizar sobre o reaproveitamento de resíduos sólidos tanto por meio dos orgânicos através da compostagem, quanto na reutilização das garrafas pets.

No que se refere a exposição de répteis e anfíbios, esta teve o objetivo de mostrar os animais ao público alvo de maneira que os sensibilizassem, chamando-se a atenção para importância de cada animal no meio ambiente e que pudesse tornar as espécies conhecidas, desmistificando os conceitos atribuídos para cada um. Na ocasião, foi realizada conversa aberta e a troca de conhecimento entre os profissionais envolvidos e a comunidade foi de grande valia na formação do conhecimento, pois possibilitam encontros dialógicos que produzem e ressignificam as experiências de cada partícipe como descrito por Sampaio et. Al. (2014).

A partir do conhecimento adequado, a participação dos moradores e a iniciativa da prática em conjunto com a unidade, torna-se-á mais fácil e efetiva, em detrimento a qualquer interação necessária, diminuindo assim, possíveis conflitos. "Com isso, a inclusão de uma Unidade de Conservação no cotidiano das populações, deve ser feita de forma educacional, planejada estrategicamente e participativa, já que quando se possui conhecimento é mais fácil opinar e julgar as ações alheias" (Cunha, 2008).

\section{Conclusão}

Percebeu-se que a metodologia utilizada permitiu desenvolver senso crítico e uma visão reflexiva nos moradores da comunidade no entorno da Unidade de Conservação de Nísia Floresta, promovendo uma maior preocupação com a preservação e conservação da Flona, compartilhamento de saberes através de uma ação educativa que envolveu toda a comunidade.

Ao realizar esse tipo de levantamento de dados, percebeu-se que tornou mais conivente atender às expectativas dos moradores da comunidade e poder enxergar suas reais perspectivas para posteriormente atendê-los de modo que através dessa sensibilização pudesse trazer mais benefícios em prol da Flona de Nísia Floresta.

Face ao que foi exposto neste artigo, compreendeu-se o quanto a percepção ambiental é um instrumento importante para interceptar a interação das comunidades que vivem no entorno das Unidades de Conservação e que a mesma deve ser amplamente utilizada como ferramenta de avaliação.

Ressalta-se que é necessário que haja uma continuidade desses estudos e práticas de EA, visto que a educação ambiental formal e não-formal é um componente essencial e permanente da educação nacional, devendo estar presente, de forma articulada, em todos os níveis e modalidades do processo educativo, como mostra a Lei 9.795/99 em seu artigo $2^{\circ}$.

Diante do cenário atual, indica-se que se realize junto à comunidade palestras voltadas para a proteção ambiental local dentro da sede da unidade de conservação, afinando-se a relação entre a comunidade com a Unidade de Conservação. 


\section{Agradecimentos}

Manifestamos nosso agradecimento ao Instituto Chico Mendes de Conservação da Biodiversidade- ICMBio por viabilizar esta pesquisa em uma das Unidade de Conservação Federal que está sob sua fiscalização, e de forma especial, agradecemos a equipe da Floresta Nacional de Nísia Floresta pelo apoio, parceria e atenção ofertada a nós. Nossos sinceros agradecimentos ao Conjunto Alto do Coqueiral por nos permitir fazer parte de sua comunidade, sua participação foi essencial para que este trabalho obtivesse êxito. Ressaltamos nossos agradecimentos à Universidade Federal do Rio Grande do NorteUFRN, pelo apoio e confiança em levar seu nome.

\section{Referências}

Alvares, C. A. (2014). Koppen's climate classification map for Brazil. Meteorologische Zeitschrift. 22(6), 711-28.

Ambiental, Coordenadoria de Educação. Programa de educação ambiental. (2011). <http://ambientes.ambientebrasil.com.br/educacao/programa s_ambienta is/programa_de_educacao_ambiental_-_ceam_(sp).html>.

Araújo, A. (2017). Cartilha de Reciclagem de Lixo. Planeta melhor. http://www.planetamelhor.com.br/site/cartilha_reciclagem/cartilha_reciclagem_web.pdf

Brasil. (2011). Decreto $n^{\circ} 7499$, de 16 de junho de 2011. Regulamenta dispositivos da Lei $\mathrm{n}^{\circ} 11.977$, de 7 de julho de 2009 , que dispõe sobre o Programa Minha Casa, Minha Vida, e dá outras providências. Diário Oficial da República Federativa do Brasil, Brasília, 16 de Junho de 2011. https://legis.senado.leg .br/norma/592918

Brasil. (2001). Decreto $n^{\circ}$ 9334, de 27 de setembro de 2001. Criação da Floresta Nacional de Nísia Floresta, no Estado do Rio Grande do Norte, e dá outras providências. Diário oficial, Brasília, 27 de setembro de 2001. http://www.planalto.gov.br/ccivil_03/DNN/2001/Dnn9334.htm

Brasil. (1998). Lei $n^{\circ}$ 9605, de 12 de fevereiro de 1998. Dispõe sobre as sanções penais e administrativas derivadas de condutas e atividades lesivas ao meio ambiente, e dá outras providências. Diário Oficial da República Federativa do Brasil, Brasília, 12 de fevereiro de 1998. http://www.planalto.gov.br/ccivil_03/leis/L9605.htm

Brasil. (1999). Lei $n^{\circ}$ 9795, de 27 de abril de 1999. Dispõe Sobre A Educação Ambiental, Institui A Política Nacional de Educação Ambiental e Dá Outras Providências. Diário Oficial da República Federativa do Brasil, Brasília, 27 abril 1999. http://www.planalto.gov.br/ccivil_03/leis/L9795.htm

Brasil. (2000). Lei $n^{\circ}$ 9.985, de 18 de Julho de 2000. Regulamenta o art. 225, § 1o, incisos I, II, III e VII da Constituição Federal, institui o Sistema Nacional de Unidades de Conservação da Natureza e dá outras providências. Diário Oficial da República Federativa do Brasil, Brasília, 18 de Julho de 2000. http://www.planalto.gov.br/ccivil_03/leis/L9985.htm

Brasil. (2007). Lei $n^{\circ} 11.516$, de 28 de Agosto de 2007. Dispõe sobre a criação do Instituto Chico Mendes de Conservação da Biodiversidade - Instituto Chico Mendes; altera as Leis n ${ }^{\text {os }} 7.735$, de 22 de fevereiro de 1989, 11.284, de 2 de março de 2006, 9.985, de 18 de julho de 2000 , 10.410 , de 11 de janeiro de 2002, 11.156, de 29 de julho de 2005, 11.357, de 19 de outubro de 2006, e 7.957, de 20 de dezembro de 1989; revoga dispositivos da Lei no 8.028 , de 12 de abril de 1990, e da Medida Provisória n ${ }^{\circ}$ 2.216-37, de 31 de agosto de 2001; e dá outras providências. Diário Oficial da República Federativa do Brasil, Brasília, 28 de Agosto de 2007. http://www.planalto.gov.br/ccivil_03/_ato2007-2010/2007/lei/111516.htm

Brasil. Ministério do Meio Ambiente. (2008). Secretaria de Articulação Institucional e Cidadania Ambiental. Os diferentes matizes da educação ambiental no Brasil: 1997-2007. Brasília. (Séries desafios da Educação Ambiental), 290p, Texto: Silvia Czapski.

Carvalho, R. D. (2006). Formação docente: Educação Ambiental na Engenharia Ambiental.

Carregosa, E. A., \& Silva, S. L. da E.; Kunhavalik, J. P. (2015). Unidade de Conservação e comunidade local: uma relação em construção. Desenvolvimento e Meio Ambiente, 35, 305-319.

Clemente, F. M. V. T., \& Heaber, L. L. (2012). Horta em pequenos espaços. EMBRAPA, 57.

Cunha, J. R. (2008). Problemas e Expectativas do Morador do Parque Municipal da Lagoa do Peri: Subsídios para uma ação de Educação Ambiental como suporte à gestão participativa. (Trabalho de conclusão de curso). Universidade Federal de Santa Catarina- UFSC, Florianópolis, Santa Catarina, Brasil.

Dalle, S. P., \& Potvin, C. (2004). Conservação de plantas úteis: uma avaliação das prioridades locais de duas comunidades indígenas no leste do Panamá. Botânica econômica, 58(1), 38-57.

Embrapa. Mapa Exploratório-Reconhecimento de Solos do município de Nísia Floresta, RN. 1991. http://www.uep.cnps.embrapa.br/solos/rn/nisiafloresta.pdf

Gerhardt, T. E., \& Silveira, D. T. (2009). Métodos de pesquisa. Coordenado pela Universidade Aberta do Brasil - UAB/UFRGS e pelo Curso de Graduação Tecnológica - Planejamento e Gestão para o Desenvolvimento Rural da SEAD/UFRGS. Porto Alegre: Editora da UFRGS.

Henriques, R. (2007). Educação Ambiental: aprendizes de sustentabilidade. Brasília: Ministério de Educação, 109.

Hirama, A. M., \& Silva, S. S. (2009). Coleta seletiva de lixo: uma análise da experiência do município de Maringá - PR. Revista Tecnológica, 18,11 -24.

ICMBio: Instituto Chico Mendes de Conservação da Biodiversidade. (2007). Brasil. http://www.icmbio.gov.br/portal 
Jesus, G. R., \& Bedritichuk, A. G. A. (2018). Autoavaliação institucional: construção e validação de um questionário para o professor. Avaliação. 23(3), 628647.

Lima, L.M.Q. (1995). Tratamento de lixo e remediação de áreas degradadas. São Paulo: OLYMPIO, José. Manual de reciclagem: coisas simples que você pode fazer. Rio de Janeiro.

Loureiro, C. F. B., \& Cunha, C. C. (2008). Educação ambiental e gestão participativa de unidades de conservação: elementos para se pensar a sustentabilidade democrática. Ambiente \& Sociedade 11, 237-253.

Maroti, P. S. (2002). Educação e interpretação ambiental junto à comunidade do entorno de uma Unidade de Conservação. 2002. 145f. Dissertação (Doutorado em Ecologia e Recursos Naturais) - Centro de Ciências Biológicas e Saúde, Universidade Federal de São Carlos, São Carlos.

Marques, D. S., \& Coutinho, J. B. (2008). Área de amortecimento do Parque Estadual das sete Passagens: as percepções dos moradores como subsídio à Educação Ambiental. (Trabalho de conclusão de curso), Universidade do Estado da Bahia- UNEB, Jacobina, Bahia, Brasil.

Medina, N. M. (2006). Educação Ambiental e Participação Comunitária. 274 f. Tese (Doutorado) - Curso de Especialização em Gestão de Recursos Hídricos em Áreas Urbanas, Universidade Federal de Santa Catarina- Departamento de Engenharia Sanitária e Ambiental, Santa Catarina.

Milano, M.S. (2000). Mitos no manejo de unidades de conservação no Brasil, ou a verdadeira ameaça. In: I Congresso Brasileiro de Unidades de Conservação. Anais. Curitiba: IAP/UNILIVRE: rede Pró-Unidades de Conservação, v.I, p.11-25.

Minayo, M. C. S. (2008). O desafio do conhecimento. Editora. Hucitec.

Minayo, M.C.S. (2015). O desafio do conhecimento. Editora. Hucitec.

Minayo, M. C. S., \& Costa, A. P (2018). Fundamentos Teóricos das Técnicas de Investigação Qualitativa. Revista Lusófona de Educação. 139-153

Ministério do Meio Ambiente (2004). Áreas Protegidas. Gestão Participativa do SNUC.

Ministério do Meio Ambiente (2017). http://www.mma.gov.br/areas-protegidas/unidades-de-conservacao/o-que-sao.

Ministério do Meio Ambiente. Instituto Chico Mendes de Conservação da Biodiversidade. (2012). Plano de Manejo da Floresta Nacional de Nísia Floresta, Nísia Floresta. Volume I/Diagnóstico. 182p.

Ministério do Meio Ambiente. Instituto Chico Mendes de Conservação da Biodiversidade. (2012). Plano de Manejo da Floresta Nacional de Nísia Floresta, Nísia Floresta. Volume II/Planejamento. 89p.

Novaes, A. K. (2019). Produção de mudas: Diagnóstico e situação atual nos viveiros do município de Rondonópolis- MT. (Trabalho de conclusão de curso). Universidade Federal de Rondonópolis- UFR, Rondonópolis, Mato Grosso, Brasil.

Richardson, R. J. (2014). Pesquisa social: métodos e técnicas. (3) Atlas.

Rodrigues, I. de S. R. (2019). Um estudo de caso sobre educação ambiental na educação infantil e ensino fundamental: Papel dos agentes multiplicadores (Trabalho de Conclusão de Curso). Instituto Federal de Educação, Ciência e Tecnologia do Piauí- IFPI. Campus Corrente, Piauí, Brasil.

Sampaio J., Santos G.C., Agostini M., \& Salvador A.S. (2014). Limites e potencialidades das rodas de conversa no cuidado em saúde: Uma experiência com jovens no sertão pernambucano. Interface. 18, 1299-1312.

Souza, C. W. S., Nascimento, L. M. B., \& Ennes, M. A. (2015). Parque Nacional Serra de Itabaiana: Implementação e gestão de uma Unidade Conservação e os moradores dos povoados de seu entorno. Desafio Online, 3(3).

Tabanez, M. F., Pádua, S. M., \& Souza, M. G. (1997). Avaliação de trilhas interpretativas para educação ambiental. Educação ambiental: caminhos trilhados no Brasil. IPE.

Torres, D. F., \& Oliveira, E. S. de. (2008). Percepção ambiental: Instrumento para educação ambiental em Unidades de Conservação. Revista eletrônica do Mestrado em Educação Ambiental, 21, 227-235.

Vasco, A. P., \& Zakrzevski, S. B. B. (2010). O estado da arte das pesquisas sobre percepção ambiental no Brasil. Perspectiva, 34 (125) 17-28.

Pinto, Q. C., Borges, P., \& Kortmann, G. M. L. (2015, Outubro). Educação Ambiental e Resíduos sólidos. SEFIC 2015 Unilasalle. 